\title{
Gruendungsgarage - A Best-Practice Example of an Academic Start-up Accelerator
}

\author{
https://doi.org/10.3991/ijep.v9i3.9876 \\ Martin Glinik \\ Graz University of Technology, Graz, Austria \\ martin.glinik@tugraz.at
}

\begin{abstract}
Over the past four decades, entrepreneurship has grown within universities faster than virtually any other area of intellectual pursuit. And it appears that the pace is accelerating with more universities seeking to develop programs and centers focused on entrepreneurship. Yet, understanding how to build entrepreneurship programs that empower and transform has remained challenging for some institutions. This paper investigated the development of an entrepreneurship program called Gruendungsgarage [1]. The Gruendungsgarage is a cooperation between the University of Graz (KFU) and the Graz University of Technology (TUG). Originally it was designed as an interdisciplinary and interuniversity teaching format offered as an elective course where students were able to work on their own real business ideas while getting assistance from university experts as well as from successful practitioners with a wide range of experience. Because of its popularity and constant improvement, Gruendungsgarage became more and more professional and over time changed its format into an academic start-up accelerator. Setting up university start-up accelerator programs has been a worldwide proven model that enables students to intensively develop their business idea into a marketable product or service in just a few months. Since the winter semester 2017/18 Gruendungsgarage has admitted not only students but also scientific staff. University and postdoctoral researchers benefit from a wide range of Gruendungsgarage services, as technical scientists with high-tech innovation get supported by experts and entrepreneurs, creating a business model suitable to their scientific discoveries.
\end{abstract}

Keywords-Entrepreneurship Lecture, Best Practice, Academic Start-Up Accelerator

\section{Introduction}

According to the changes in the economy and workforce, entrepreneurship and corresponding education are subjects of current interest throughout Europe. Lepuschitz et al. (2018) determine that these changes call for an entrepreneurial mindset. They argue that through an appropriate education at school and university levels, students can acquire relevant skills and mindset required for entrepreneurship [2]. Several research articles focus on the creation of entrepreneurship programs offered at universities. It is, therefore, valuable to perform a qualitative perspective on the educational practices of 
an entrepreneurial program called Gruendungsgarage [3]. Due to a five years' experience, the teaching program serves as a best practice approach to entrepreneurship education within tertiary education. The paper provides an overview of procedures, findings and approaches in structuring entrepreneurship education within the program. Originally, the Gruendungsgarage started as an interdisciplinary teaching format offered as an elective course in order to provide support for preparing innovative and knowledge-based start-up projects developed by students of the University of Graz (KFU). A volume extends over one university semester and is divided into several teaching and workshop phases. After two successful volumes, the University of Graz (KFU) enter into a partnership with the University of Technology (TUG) with the aim to attract the attention of students with a technical background and an inclination to start a business. On the one hand this partnership increased the educational diversity among the participants. On the other hand, the number of technology-oriented start-up projects hosted by the Gruendungsgarage also increased due to this cooperation. The focus of the program is on practical activities which reflects the entrepreneurship reality in a controlled environment. Practical tasks are mainly used to teach entrepreneurship, rather than a reliance on traditional classroom teaching. Program leaders originate from both academia and industry, with the aim of blending theoretical and practical knowledge [4]. The proportion of theory-based knowledge transfer is deliberately kept small and the teaching sessions are always outside a typical lecture room to enable a creative work climate. As a result, the participants can experiment with their business ideas get them ready for market and prepared for founding a start-up company. Another characteristic is the group-based learning method, which allows the teams to get an idea about how it is to work with a new venture team [5]. The teambuilding process is a very important experience for each individual to become aware of their role inside the team to define the areas of responsibility of each founder.

The aim of this paper is to introduce the proven concept of the Gruendungsgarage and to examine the support services participants receive during the accelerator program. Furthermore, we are interested in understanding the success factors of start-up initiatives in higher education to deliver training that meets the stakeholder needs.

\subsection{Expanding target audience to increase the scope}

Benefiting from the strategic project "entrepreneurial university" which was launched at the TUG in 2015, the Gruendungsgarage moves into the spotlight of the entrepreneurial education and paves the way for academic start-ups. The aim of this new strategic orientation was to stimulate the entrepreneurial spirit of the students but also employees and develop third mission policies within the TUG. [6] As a result, the Gruendungsgarage expanded its target audience - this means that services are not for students exclusively. Since the winter semester 2017/18, scientific staff is also eligible to apply proposing their business ideas as well as benefiting from the same kind of support and network use.

The opportunity for scientific staff to participate in the Gruendungsgarage was internally promoted to draw the attention of the new target group towards new entrepreneur- 
ial service offers. Furthermore, the Gruendungsgarage gets integrated into the postgraduate training catalogue of the TUG to make it more visible for the scientific staff. After attending the program, they get an official confirmation that is also credited to them as a further education.

According to a recent study of the IfM Bonn, many good ideas arise at universities but the implementation is rarely tackled. [7] For this reason a recently launched national funding program called "Spin-off Fellowship" should support scientists to commercialize their intellectual property. Over a period of 18 months, the scientists are released from their work duties in order to develop their research results, create a business plan and prepare their business formation after finishing the funding program. As an integrated component of the strategic project "entrepreneurial university" at the TUG, the Gruendungsgarage assembled a comprehensive training catalogue to provide the fellows with a broad range of business and legal knowledge to teach them entrepreneurial skills.

\subsection{Success factors of the gruendungsgarage}

The ongoing success of this format is based on special characteristics that make the Gruendungsgarage an academic start-up accelerator and hence more than just a lecture. One of the features represents the opportunity for students and scientific staff to work on their own business idea which increases their motivation and willingness to participate. After their successful participation, all members get the Gruendungsgarage certificate, and students also benefit from it by receiving 2 ECTS credits. The latter is more a symbolic reward in consideration of the effort they provide during the semester.

Beyond that, Gruendungsgarage offers entrepreneurs the support of university lectors with an expertise in Entrepreneurship as well as an extensive network of experienced business professionals. The collaboration with people interested in mentoring is an essential part of the program to improve the long-term functioning of start-ups and help them to develop their network. There is a strong interest by business professionals to become mentors why new business professionals apply for the work as a mentor on a regular basis. The organizers of the Gruendungsgarage strive to find every team two complementary mentors that suit their situation, needs and development stage. The mentors' background, know-how and interests is taken into account to ensure maximum compatibility. Business professionals play a significant role as they guide the teams during the whole semester and provide feedback at an early stage where they haven't already started a business. In that way, the teams may easily rearrange or modify their business ideas without losing their precious time.

Due to the increasing awareness, Gruendungsgarage can rely on 26 active mentors who cover almost every field of starting a business. Their consulting services range from business modelling, design-thinking, inbound logistics and online marketing, intellectual property right, and software development to legal and tax advice.

Once a semester, the Gruendungsgarage organizes so-called "mentoring days" where the teams get the chance of a consultation appointment to seek the advice of all mentors and not only from those who are assigned to them. This special event is an organizational improvement. Due to an evaluation of the teaching program by the participants 
as well as a survey of the mentors has shown that it is particularly difficult for teams and mentors to arrange a suitable date for everyone. The "mentoring days" enable a more efficient time management and lead to a more intensive exchange between the two parties. In order to get as many mentors as possible for several hours at a time, a doodle survey was performed. After the dates were determined with the mentors, the teams are provided with a great opportunity to book a time slot with each mentor, allowing participants to receive a comprehensive consultation from different experts in only one session.

A further improvement of the teaching format is the stronger integration of alumni in the knowledge transfer and the exchange of experience with beginners of the Gruendungsgarage. Every semester, one workshop is led by alumni who successfully started a business after their time at the Gruendungsgarage. These alumni briefly present an outline of their career and share their experience with the teams of the current volume. But they do not only talk about aspects of their success - they also share their failures and lessons and what they have learnt from them. This is a great opportunity for the newcomers to see what it takes to become an entrepreneur and which challenges are waiting for them after finishing the program.

An additional initiative was established to enhance the commitment of the alumni and the mentors of the Gruendungsgarage in the summer semester 2018. The so called "alumni academy" is a regular event where alumni and mentors can exchange views on current topics and issues of the startup scene. The goal is to learn from each other, to exchange ideas and to maintain the common network. The "alumni academy" offers space for discussions about challenges related to entrepreneurial growth and which aspects of international expansion are especially important for startups and young companies. The input is provided by alumni of the Gruendungsgarage network which are confronted with these challenges and report from their experience.

Further assistance is offered in the fields of financing and funding. All of the teams which are currently hosted by the Gruendungsgarage are in the (pre-) seed phase where public funding represents a significant source of income. Therefore, the teams get advice which funding institutions are the most promising to address in the early stage and what they need to consider at the submission of the funding application.

Besides the mentors and the alumni, the network of the Gruendungsgarage also includes investors and business angels. It offers to the promising teams start-up funding to facilitate the realization of their own business ideas. Although the teams get support through the regional and national funding agencies in Austria, private investors are essential at a certain point, as it makes them important partners of the Gruendungsgarage.

\section{Structure of the Gruendungsgarage}

Every university semester, students and scientific staff wishing to start-up a business can apply for the program by sending an online application to the executive board of the Gruendungsgarage. In a semi-structured online form, the applicants shortly describe their initial situation, the business idea, the current status and the next steps they are planning in regard to their project. The submission deadline ends about two weeks after 
the official semester start. Subsequently, a team of experts evaluates all the business ideas in terms of the level of innovation as well as the potential and accessible scalability of the idea. As a part of the evaluation, attention on the maturity level of the business ideas are given as well to ensure not having projects at the Gruendungsgarage who are already on the brink of market entry because the aim of the accelerator program is to support idea projects which are situated in the (pre-) seed phase. In this early stage, university experts and external mentors provide valuable input through a balanced mixture of strategic knowhow and practical experience.

The Gruendungsgarage offers students and scientific staff an extensive support why a maximum of ten teams can participate at the accelerator program per semester. Throughout the program, the teams receive a wide range of start-up support. This includes class-room-lessons, workshops, consulting sessions, exercises, discussions with the group, and also with alumni teams of the Gruendungsgarage who have already founded a business. The entire course of events is illustrated in Figure 1 and can be described as follows [8].

After the submission deadline all applications from students and scientific staff are collected and evaluated. Those who do not meet the requirements are sorted out by a team of experts who finally determine the ten best business ideas and link them to those mentors whose field of expertise best matches the idea.

Shortly after the decision, the selected teams get informed about their qualification and get invited to a kick-of event. This event marks the official start of the accelerator program where the teams present their business ideas to the whole group in order to get feedback. Furthermore, it helps the teams to get to know each other and to start networking. During the kick-off event, the teams also get in touch with their assigned mentors for the first time to set their target agreements.

As Figure 1 shows, after the kick-off event several phases begin. The first two weeks are characterized by a start-up phase where the teams mainly work on their business models. Generally, the teams enter the Gruendungsgarage with a rough business idea only and usually do not deal with a business model. In the second phase, the teams receive some workshops which deal with start-up relevant topics like business model development, design-thinking, online- and growth marketing, intellectual property rights and legal and tax advice. 


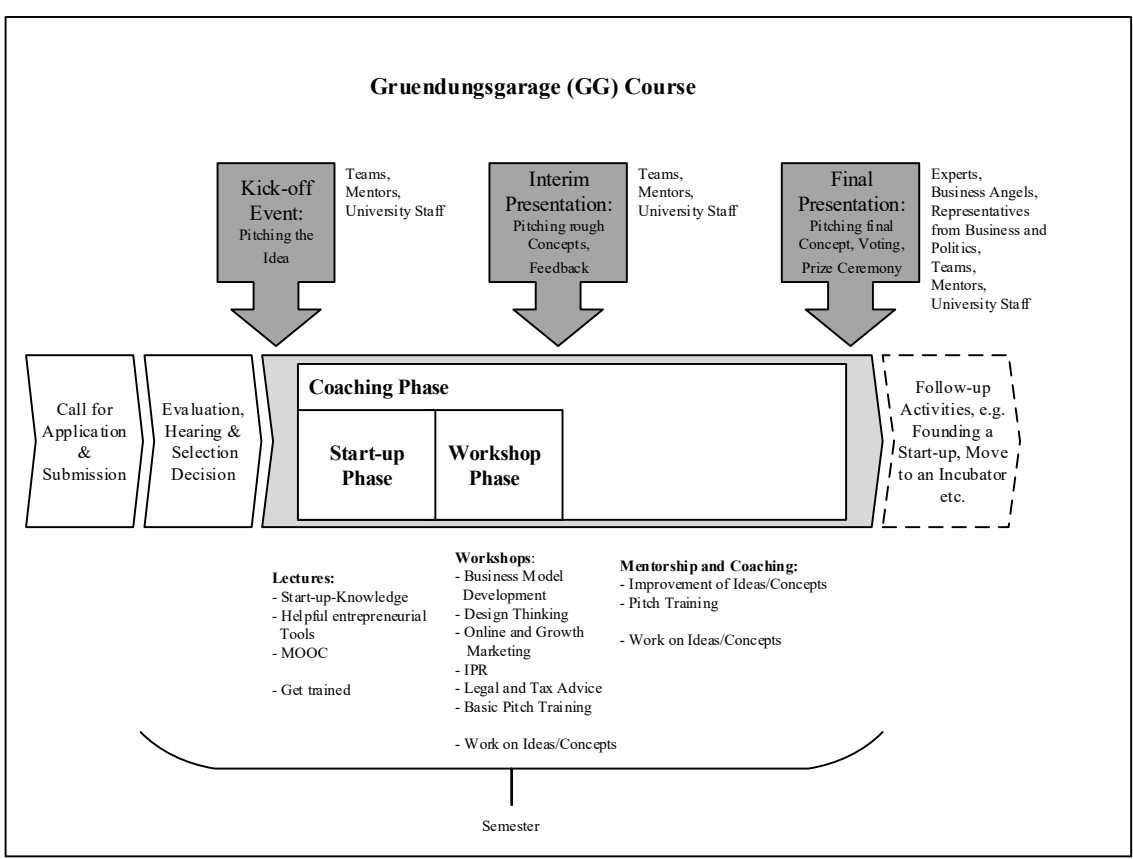

Fig. 1. Structure of the Gruendungsgarage

Over the numerous volumes, this workshop phase has changed in terms of period and frequency in which the workshops are offered. The program leaders of the Gruendungsgarage realized the need for workshop-days instead of several workshop-units, which usually used to take two hours. The disadvantage of the previously offered workshop-units is that just when the teams reach a productive working phase, they have to stop because of the short lessons. It turned out that the teams are much more productive if they complete full workshop-days where they get time to focus on certain tasks and acquire the skills to start a business.

Another improvement of the workshops was the use of massive open online courses (MOOCs) which are combined with the business model workshop. A couple of days before the workshop starts, the participants need to watch online videos about creating a business model.

These videos were specially made to support the teams and make it easier for them to work with a business model canvas on the first workshop day. The past showed that participants who have never worked with a business model canvas before had frequently difficulties to follow the instructions and so they often ran out of time. It turned out, that MOOCs were the right approach to raise the output of the workshop which leads to an enrichment of the knowledge transfer [9].

After about six weeks, there is an interim presentation where the teams present the progress and their results to the whole group. Again, every team receives feedback concerning the pitch, important developmental steps and their level of target achievement. 
The third phase is called "coaching phase" and extends over the whole semester. It is characterized through discussions with the mentors, experts and alumni of the Gruendungsgarage. The aim of this coaching sessions is the development of the business models of the teams to get them ready for market. Beside the workshop-phase, the procedure of the coaching-phase has also changed over time. In former volumes, the participants were advised to make individual appointments with mentors from businesses and university to get feedback on their elaborated results. However, the experience has shown that it is difficult to find common dates where both, the team members and the mentors, would have time. Because of this reason, the so-called "mentoring-days" were introduced to offer the teams one to two days where the majority of the mentors are available for several hours. Especially for the busy mentors, this organizational change represents an enormous relief.

The Gruendungsgarage concludes with a final presentation at the end of the semester where the teams get the opportunity to present their business ideas to an audience consisting of investors, business angels and people from the local start-up scene. The audience votes for the top three teams who receive great prizes from sponsors and partners of the Gruendungsgarage [8].

\section{Facts and Figures}

As seen in Figure 2, a total of 205 students and scientific staff took part at the Gruendungsgarage during the last five years which led to a support of 101 projects/teams during this time. 33 out of these 101 teams actually started a business after attending the academic start-up accelerator and 28 of them are still operating on the market. A study was conducted to ask for the number of jobs being created by these start-ups. It turned out that more than 130 jobs were created which is a valuable contribution to the domestic economy.

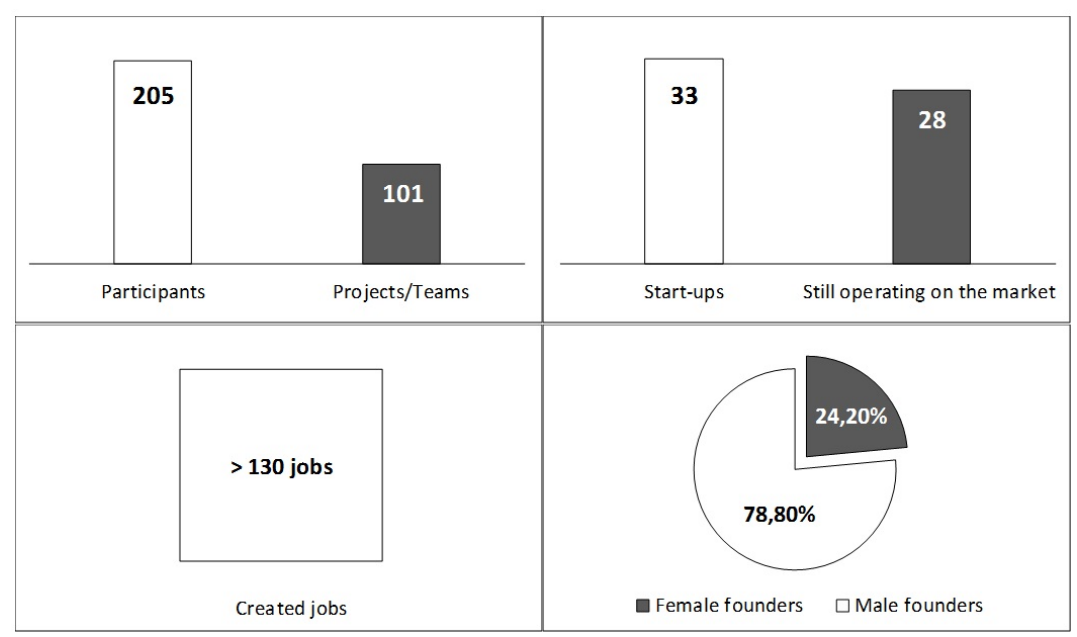

Fig. 2. Key figures of the Gruendungsgarage Vol. 1-11, retrieved December 2018 
The percentage of women among the 28 active start-ups of the Gruendungsgarage is $24.20 \%$ which is well above the Austrian and the European average. According to a study by the European Startup Monitor (ESM), the percentage of female start-up founders in Austria is only $7,1 \%$ and in Europe it is $14,8 \%$ on average [10]. Thus, the Gruendungsgarage represents a true diversity format through its percentage of female startup founders.

In the last four volumes (volume 8-11), the data collection was systematized to allow a more detailed analysis of key figures such as:

- University affiliation of the teams

- Team composition

- Educational background of the participants

A notable aspect of the data analysis was the number of applied and selected teams of the Graz University of Technology. While initially, most of the applicants were students or members of the KFU, the number of applied and selected teams from the TUG has increased during the last four volumes. More and more teams with a technical background are interested in participating in the accelerator program to benefit from an authentic entrepreneurship experience, as it exposes academic participants to real world start-up problems and opportunities.

Figure 3 compares the number of teams that applied for the Gruendungsgarage and those that have been selected, labeled by their university affiliation.

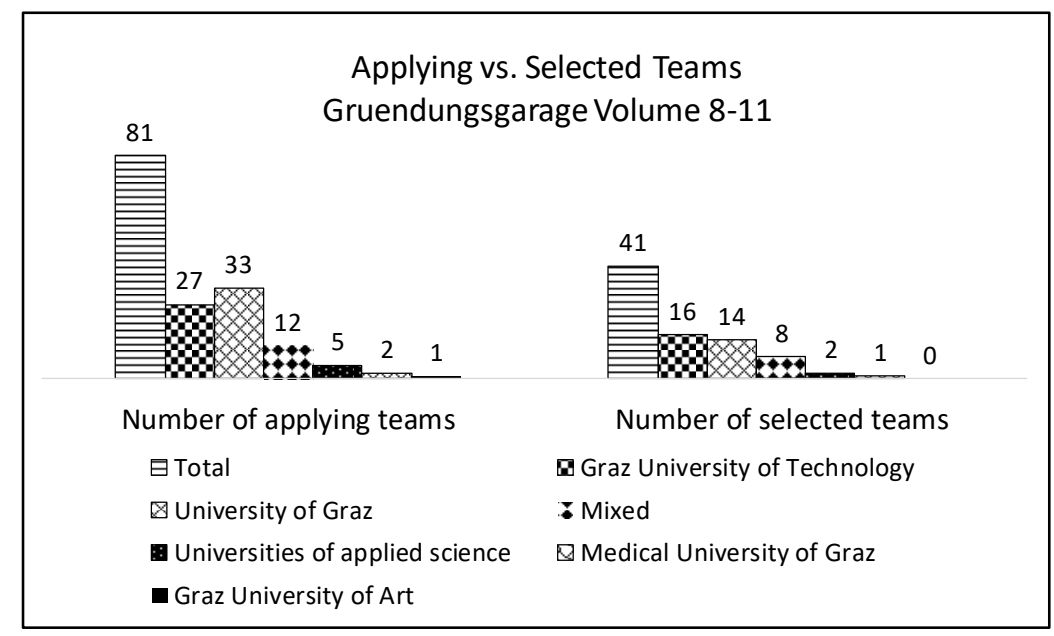

Fig. 3. Applying vs. Selected Teams at the Gruendungsgarage Vol. 8-11

Although the number of participants from universities with a technical focus is increasing, there is still a lack of heterogeneous teams. Over the last four volumes there were only eight mixed teams out of 41 with a different field of study/discipline.

Furthermore, there is a trend towards digitalization in terms of the products, processes, and business models of the selected teams and those who are currently in the 
start-up process. For the development of digital business models, programming skills are an advantage that qualifies students and scientists of the TUG and universities of applied science to participate at the Gruendungsgarage [11].

To extend the investigation, the e-mail correspondence between the program leaders and the teams of the Gruendungsgarage were analyzed to get an idea of the content exchanged via this medium. It turned out that there is little exchange regarding subjectspecific issues. Instead, mainly organizational topics are discussed via e-mail. Frequently, teams contact program leaders of the TUG with technical questions, with the intent to get access to specific institutes at Graz University of Technology that can offer them technical support for their products. However, strategic questions concerning the business models are typically discussed in person during one of the numerous workshops, meetings, or events of the Gruendungsgarage.

\section{Discussion and Outlook}

After ten volumes and more than 25 successfully realized projects, the Gruendungsgarage has demonstrated its valuable contribution for students and scientific staff interested in starting their own business. Due to the increasing interest of participants with a technical background, the range of support services needs a constantly review to meet the needs of the different stakeholders. Therefore, the service offerings of the Gruendungsgarage gets constantly evaluated and improved in order to meet the needs of a broader and heterogeneous group of students and scientific staff [12].

Nevertheless, the latter group is still underrepresented at the Gruendungsgarage and needs more attention to show them the possibilities and advantages of an entrepreneurial career. It has shown that generally PhD-students or postdoctoral researchers with a fixed-term employment contract had participated the program during the last few volumes while scientific staff with a contract of employment of indefinite duration showed practically no intention in becoming an entrepreneur. An investigation of the factors which are beneficial or obstructing for university scientist to attend an entrepreneurial program and thus effectively start a business would be helpful to effectively promote an entrepreneurial program to this group. In any case, it is essential to create an entrepreneurial awareness throughout the entire university to foster individuals who have the motivation and capacity to identify an opportunity and pursue it in order to produce new value and economic success.

A further possibility for optimizing the Gruendungsgarage refers to the diversity within the teams. Diverse people are sorely underrepresented in the business world particularly in start-ups - and the Gruendungsgarage is no exception. Until now, many teams consisted of students or scientists from the same university or the same discipline, which limited their mindset and reduced their creativity [13]. To remedy such unsatisfactory tendencies, the program leaders thought about a change in the application process. For instance, the teambuilding process could take place at the beginning and not before the Gruendungsgarage starts. In a kind of matchmaking, potential founders with different fields of expertise would get to know each other and exchange ideas about possible partnerships before they start the regular program. A second modification of 
the teaching format aims to adopt an approach where universities exploit their intellectual property generated through theoretical and applied research. According to this approach, the Gruendungsgarage could offer students and scientific staff access to the patent archive where they analyze all the patents, pick an idea, and consider how they can commercialize it. This setup could lead to a format where participants of the Gruendungsgarage are no longer forced to apply with a business idea but still prove their entrepreneurial skills.

Five years of experience have shown that the teaching format as the Gruendungsgarage is essential for the local start-up scene in order to get a comprehensive support at a very early start-up phase. The numerous applications verify the interest of particularly students and scientific staff in the topic entrepreneurship which can be used as an evidence that there is a remarkable demand for more practical entrepreneurship education.

\section{$5 \quad$ References}

[1] S. Hoskinson and D. F. Kuratko, "Innovative Pathways for University Entrepreneurship in the 21st Century," Advances in the study of entrepreneurship, innovation \& economic growth, vol. 24, p.1, 2014. https://doi.org/10.1108/s1048-473620140000024016

[2] W. Lepuschitz,G. Koppensteiner, U. Leeb-Bracher, K. Hollnsteiner, and M. Merdan, "Educational Practices for Improvement of Entrepreneurial Skills at Secondary School Level," International Journal of Engineering Pedagogy, vol. 8, no 8, pp. 111-112, 2018. https://doi.org/10.3991/ijep.v8i2.8141

[3] N. Antal, B. Kingma, D. Moore, and D. Streeter, "University-wide Entrepreneurship Education," in Innovative Pathways for University Entrepreneurship in the 21st Century, vol 24, Advances in the Study of Entrepreneurship, Innovation and Economic Growth, vol 24, JAI Press, pp. 227-254, 2014. https://doi.org/10.1108/s1048-473620140000024009

[4] C. Nieuwenhuizen, D. Groenewald, J. Davids, L.J. Rensburg, and C. Schachtebeck, „Best practice in entrepreneurship education," Journal of Problems and Perspectives in Management, vol 14, no 3, pp. 528-536, 2016. https://doi.org/10.21511/ppm.14(3-2).2016.09

[5] R. Harms, "Self-regulated learning, team learning and project performance in entrepreneurship education: Learning in a lean startup environment," Journal of Technological Forecasting \& Social Change, vol. 100, pp. 21-28, 2015. https://doi.org/10.1016/j.techfore.2015.02.007

[6] Online Pressestelle der Technischen Universität Graz, „Ein starkes Team für die TU Graz Das Rektorat 2015 - 2019 - Die unternehmerische Universität als zusätzlicher strategischer Schwerpunkt zu Internationalisierung, Kooperation und Profilbildung," September 2015. [Online]. Available: https://pressearchiv.tugraz.at/pressemitteilungen/2015/29.09.2015.htm [Accessed Nov. 7, 2018]. https://doi.org/10.1007/s00735-015-0580-9

[7] T. Bijedić, S. Chlosta, S. Hossinger, A. Kasdorf, S. Schneck, C. Schröder, and A. Werner, in collaboration with S. Nielen, and S. Oschmann, "Gründungserfolg von Wissenschaftlern an deutschen Hochschulen, IfM Bonn," IfM-Materialien no. 257, July, 2017.

[8] S. Vorbach, "Lecturing Entrepreneurship at Graz University of Technology - The Case of Gruendungsgarage," presented at $20^{\text {th }}$ International conference on Interactive Collaborative Learning, Budapest, Hungary, 2017.

[9] G. Mayende, A. Prinz, G. Maurice, N. Isabwe, and P.B. Muyinda, "Learning Groups in MOOCs: Lessons for Online Learning in Higher Education," International Journal of Engineering Pedagogy, vol. 7, no. 2, p. 5, 2017. https://doi.org/10.3991/ijep.v7i2.6925 
[10] T. Kollmann, C. Stöckmann, S. Hensellek, and J. Kensbock, "European Startup Monitor," europeanstartupmonitor.com, 2016. [Online]. Available: https://europeanstart upmonitor.com/fileadmin/esm_2016/report/ESM_2016_PPT_EN.pdf. [Accessed Nov. 8, 2018].

[11] E. Poandl, M. Glinik, and R. Taferner, "Digitalisierung in Academic Startups - Trends bei Gründungsprojekten der Gründungsgarage Graz," presented at 22nd Annual Interdisciplinary Conference on Entrepreneurship, Innovation and SMEs, Stuttgart, Germany.

[12] P. Holzmann, E. Hartlieb, and M. Roth, "From Engineer to Entrepreneur - Entrepreneurship Education for Engineering Students: The Case of the Entrepreneurial Campus Villach," International Journal of Engineering Pedagogy, vol. 8, no. 3, p. 30, 2018. https://doi.org/10.3991/ijep.v8i3.7942

[13] R. Novellus, "Why Diversity Is Needed In Startups," June 2016. [Online]. Available: https://www.forbes.com/sites/yec/2017/06/15/why-diversity-is-needed-instartups/\#6fcbf08476ea [Accessed Nov. 15, 2018].

\section{$6 \quad$ Author}

Martin Glinik is a research assistant at the Institute of General Management and Organisation at Graz University of Technology, Kopernikusgasse 24/IV, 8019 Graz, Austria. He holds a Master degree in business economics and a graduation of a higher technical college of engineering. His research interests focus on the field of Entrepreneurship and Business Models of start-ups. Martin is a PhD candidate in Business Administration and his work at an academic start-up accelerator is dedicated to the development of an entrepreneurial university and to strengthening the local start-up scene.

Article submitted 2018-11-18. Resubmitted 2019-01-16. Final acceptance 2019-04-25. Final version published as submitted by the authors. 